\title{
1,2,3,4-Tetrahydro-1,4,5,8-tetraazaanthracene revisited: properties and structural evidence of aromaticity loss
}

\author{
Arnault Heynderickx, Sébastien Nénon, Olivier Siri ${ }^{*}$, Vladimir Lokshin \\ and Vladimir Khodorkovsky*
}

\author{
Full Research Paper \\ Address: \\ Aix Marseille Université, CNRS CINaM UMR 7325 Campus de \\ Luminy, case 913,13288 , Marseille, France \\ Email: \\ Olivier Siri ${ }^{*}$ - olivier.siri@univ-amu.fr; Vladimir Khodorkovsky ${ }^{*}$ - \\ khodor@cinam.univ-mrs.fr \\ * Corresponding author \\ Keywords: \\ aromaticity; density functional calculations; heterocycles; hydrogen \\ bonds; X-ray structures
}

\author{
Beilstein J. Org. Chem. 2019, 15, 2059-2068. \\ doi:10.3762/bjoc. 15.203 \\ Received: 02 June 2019 \\ Accepted: 10 August 2019 \\ Published: 28 August 2019 \\ Associate Editor: P. Schreiner \\ (c) 2019 Heynderickx et al.; licensee Beilstein-Institut. \\ License and terms: see end of document.
}

\begin{abstract}
The synthesis and properties of 1,2,3,4-tetrahydro-1,4,5,8-tetraazaanthracene (THTAA) - a heterocycle involving both $>\mathrm{N}-\mathrm{H}$ donating and $=\mathrm{N}$ - accepting moieties - have been reinvestigated. Unlike previously reported, THTAA is a thermally stable compound that can be re-sublimed at $300-310^{\circ} \mathrm{C}$ without decomposition. Controlled introduction of substituents at the nitrogen atoms of THTAA led to variation of its electron donor/acceptor capability that allowed fine-tuning the absorption properties. The propensity of these compounds and a number of its derivatives to form infinite chains involving $>\mathrm{N}-\mathrm{H} \cdots \mathrm{N}=$ and $>\mathrm{N}-\mathrm{H} \cdots \mathrm{Hal}{ }^{-} \cdots \mathrm{N}^{+}$atoms is demonstrated by X-ray structure analysis. The DFT level optimized and experimental geometry of THTAA and its derivatives show considerable loss of aromaticity within the quinoxaline moiety.
\end{abstract}

\section{Introduction}

Quinoxaline derivatives $\mathbf{1}$ - also called benzopyrazines - are among the most studied heterocycles owing to their remarkable implications in many areas of chemistry, biology, medicine and agriculture. The literature on these derivatives as well as their saturated analogs 2 , covering their chemistry and applications up to 2012, has been thoroughly reviewed, in particular, in three volumes of Chemistry of Heterocyclic Compounds (Editors A. Weisssberger et al.) [1-3] and a recent book [4]. During the past years azaacenes attracted interest as potential components of light emitting diodes and electronic devices [5-7]. Surprisingly, little is known about 1,2,3,4-tetrahydro-1,4,5,8-tetraaza- anthracene (1,2,3,4-tetrahydropyrazino[2,3-g]quinoxaline, THTAA, 3) combining the structural elements of both $\mathbf{1}$ and $\mathbf{2}$ (Figure 1), although its isolation and preparative scale synthesis has been described more than 50 years ago $[8,9]$ and modified later [10]. A strongly fluorescent compound, 3, has been isolated from the reaction of ethylenediamine with noradrenaline, 2-methylnoradrenaline, adrenolone, 3,4-dihydroxymandelic acid or catechol [8].

The reaction with 2,5-dihydroxy-p-benzoquinone (4) under a stream of air affording $\mathbf{3}$ in $50 \%$ yield was proposed as the most 
1

$$
\overbrace{n^{\prime}}^{N^{\prime}}
$$

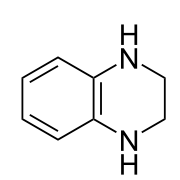

2

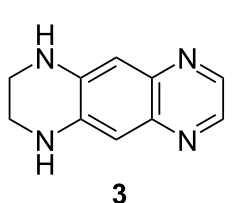

3
Figure 1: Quinoxaline derivatives 1-3.

convenient method of preparation (Scheme 1) [8]. This compound was described as yellow plates (from ethanol), which decomposed at about $300{ }^{\circ} \mathrm{C}$ giving a small amount of almost colorless crystalline sublimate identified as 1,4,5,8-tetraazaanthracene (5) [8]. The structure of $\mathbf{3}$ as the 1,2,3,4-tetrahydro isomer has been assigned considering only indirect evidences so that the structure corresponding to the 1,2,6,7-tetrahydro isomer cannot be excluded (no NMR data have been reported so far). A well related known example involves the correct structure of fluorindine (5,14-dihydro derivative of quinoxalino[2,3$b$ ]phenazine), which has been fully established in 1987 by the ${ }^{1} \mathrm{H}$ NMR spectrum splitting patterns [11], the compound assumed to be the 5,12-dihydro isomer since 1890 [12].

1,2,3,4-Tetrahydro-1,4,5,8-tetraazaanthracene (THTAA, 3) bearing the electron-donating $\mathrm{NH}$ and accepting $=\mathrm{N}$ moieties allows further modifications at these units to achieve finetuning of the light absorption and redox properties. In the course of this study, we also expected that these derivatives could serve as interesting components of supramolecular structures that can assemble in a predictable way owing to the formation of hydrogen bonds, an approach known as 'crystal engineering' (see, for instance, [13,14] and references therein). Indeed, whereas several two-component molecular systems cocrystallizing in a special layered way involving pyrazine, quinoline and phenazine as the H-bond acceptor and hydroquinones or chloranilic acid as the H-bond donors (the $\mathrm{O}-\mathrm{H} \cdots \mathrm{N}=\mathrm{C}$ H-bonds) are known $[15,16]$, the examples of the $\mathrm{N}-\mathrm{H} \cdots \mathrm{N}=\mathrm{C}$ bonds are less numerous and involve mostly aminopyrimidines and imidazoles [13,14]. Derivatives of $\mathbf{3}$ can be of special interest as flexible supramolecular synthons $[14,17]$ owing to the presence of two H-donor $(\mathrm{N}-\mathrm{H})$ and two $\mathrm{H}$-acceptor $(\mathrm{N}=\mathrm{C})$ sites that can lead to well organized $\mathrm{H}$-bonded arrangements in the solid state. Moreover, the pres- ence of two different types of nitrogen atoms affords the possibility to be selectively substituted at the desired position.

Here we revisited the synthesis and purification of THTAA (3), and report on the results of our investigation based on the quantum mechanical calculations, X-ray structures and electronic absorption spectra of $\mathbf{3}$ and a number of its derivatives.

\section{Results and Discussion Synthesis, purification and chemical modification of THTAA}

Derivative 3 was prepared from 2,5-dihydroxy-p-benzoquinone and ethylenediamine as brownish-yellow solid according to the recommended procedure (Scheme 1) [8].

Crystallization from butyl acetate produced yellow crystals of THTAA (3) in about 50\% yield, still slightly brownish, along with the unidentified dark brown poorly soluble solid. The crystallized samples of THTAA can be sublimed at about $300{ }^{\circ} \mathrm{C}$ at ambient pressure without decomposition affording bright yellow needles in contrast to the observation of decomposition in the original paper [5]. The formation of tetraazaanthracene (TAA, 5) was observed upon attempts to sublime the brown byproduct about $200-210{ }^{\circ} \mathrm{C}$ affording colorless crystals. The NMR spectrum corresponded to $\mathbf{5}$ (described, sometimes, as light yellow solid $[18,19])$.

It is worth of noting that sublimed $\mathbf{5}$ does not fluoresce so that previously observed fluorescence [20] and yellowish color of 5 stems in fact from the admixture of $\mathbf{3}$.

We first envisaged the protonation of $\mathbf{3}$ in order to isolate the corresponding diiminium salts which should have a stronger electron-withdrawing character (compared to 3). Acidification of 3 in ethyl acetate by an excess of $\mathrm{HCl}$ or $\mathrm{HBF}_{4}$ yielded red salts $6 \mathbf{a}$ and $\mathbf{6 b}$ in 85 and $78 \%$ yield, respectively (Scheme 2). The ${ }^{1} \mathrm{H}$ NMR spectra of both salts are similar. We then decided to alkylate 3 in order to overcome the inherent $\mathrm{pH}$-dependent behavior of salts $\mathbf{6}$. Analogously to 4-aminopyridine [21], only the $\mathrm{sp}^{2}$ nitrogen atom of the quinoxaline moiety undergoes alkylation by methyl iodide or propyl iodide in $\mathrm{MeCN}$ for 2 days to afford $\mathbf{7 a}$ and $\mathbf{7 b}$ in 90 and $92 \%$ yields, respectively<smiles>O=C1C=C(O)C(=O)C=C1O</smiles>

4

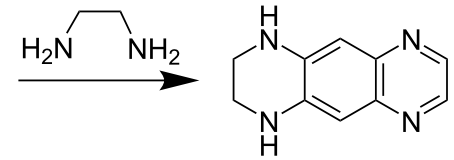

3<smiles>c1cnc2cc3nccnc3cc2n1</smiles>

5 
(Scheme 2). The dimethyl derivative $\mathbf{8}$ can be prepared using a stronger methylating agent such as trimethyloxonium tetrafluoroborate. Comparison of the ${ }^{1} \mathrm{H}$ NMR spectra clearly demonstrated the formation of $\mathbf{8}$ which shows 5 signals whereas the spectrum of $\mathbf{7 a}$ (or $\mathbf{7 b}$ ) exhibits 12 resonances. Next, we found that acylation of $\mathbf{3}$ with a large excess of acetic anhydride or pivaloyl chloride in the presence of $N, N$-diisopropylethylamine afforded 1,4-diacyl derivatives 9 and 10a in high yields. Interestingly, the reaction with pivaloyl chloride in $\mathrm{MeCN}$ in the presence of triethylamine at $80{ }^{\circ} \mathrm{C}$ gave the monosubstituted derivative $\mathbf{1 0 b}$ in about $48 \%$ yield even with the excess of the acylating agent. The ${ }^{1} \mathrm{H}$ NMR spectra of 9 and $\mathbf{1 0 a}$, like in the case of derivative $\mathbf{8}$, indicated a symmetrical structure expected for the bis-acylated products.

\section{Molecular structures}

The molecular structures of compounds $\mathbf{3}, \mathbf{6 a}$, and $7 \mathbf{a}$ have been established by an X-ray diffraction study. The molecular geometry is strongly affected by the presence of networks of intramolecular short distances: $=\mathrm{N} \cdots \mathrm{H}-\mathrm{N}<($ derivatives 3 and $\mathbf{7 a})$ and $\mathrm{N}-\mathrm{H} \cdots \mathrm{Cl}(\mathbf{6 a})$. The experimental (averaged) and calculated selected bond lengths are listed in Table 1. There are two independent molecules of $\mathbf{3}$ in the cell, bound with the short $=\mathrm{N} \cdots \mathrm{H}-\mathrm{N}<$ hydrogen bond of $2.184 \AA$ (Figure 2). Examination of the bond distances within the N2-C1-C14-C13-N12, $\mathrm{N} 5-\mathrm{C} 6-\mathrm{C} 7-\mathrm{C} 8-\mathrm{N} 9$ atom chains and the respective bond lengths of the second independent molecule of $\mathbf{3}$ reveals a contribution of the intramolecular charge transfer from the elec-

\begin{tabular}{|c|c|c|c|}
\hline Compound & Bond & Experimental ${ }^{\mathrm{a}}$ & Calculated \\
\hline \multirow[t]{7}{*}{3} & C1-N2 & 1.367 & 1.391 \\
\hline & C1-C14 & 1.371 & 1.376 \\
\hline & C13-C14 & 1.405 & 1.411 \\
\hline & $\mathrm{C} 13-\mathrm{N} 12$ & 1.363 & 1.355 \\
\hline & $\mathrm{C} 11-\mathrm{N} 12$ & 1.327 & 1.317 \\
\hline & $\mathrm{C} 1-\mathrm{C} 6$ & 1.445 & 1.441 \\
\hline & C8-C13 & 1.425 & 1.430 \\
\hline \multirow[t]{7}{*}{$6 a$} & $\mathrm{C} 1-\mathrm{N} 2$ & 1.335 & 1.329 \\
\hline & $\mathrm{C} 1-\mathrm{C} 14$ & 1.384 & 1.398 \\
\hline & C13-C14 & 1.389 & 1.381 \\
\hline & C13-N12 & 1.345 & 1.357 \\
\hline & $\mathrm{C} 11-\mathrm{N} 12$ & 1.370 & 1.361 \\
\hline & $\mathrm{C} 1-\mathrm{C} 6$ & 1.469 & 1.477 \\
\hline & C8-C13 & 1.441 & 1.459 \\
\hline \multirow[t]{10}{*}{$7 a$} & C1-N2 & 1.342 & 1.352 \\
\hline & C1-C6 & 1.378 & 1.393 \\
\hline & C5-C6 & 1.403 & 1.393 \\
\hline & C5-N4 & 1.365 & 1.371 \\
\hline & $\mathrm{C} 2-\mathrm{N} 1$ & 1.339 & 1.366 \\
\hline & C2-C3 & 1.380 & 1.374 \\
\hline & C3-C4 & 1.388 & 1.409 \\
\hline & C4-N3 & 1.357 & 1.408 \\
\hline & $\mathrm{C} 1-\mathrm{C} 2$ & 1.457 & 1.458 \\
\hline & C4-C5 & 1.449 & 1.448 \\
\hline
\end{tabular}

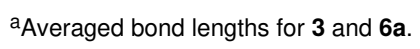

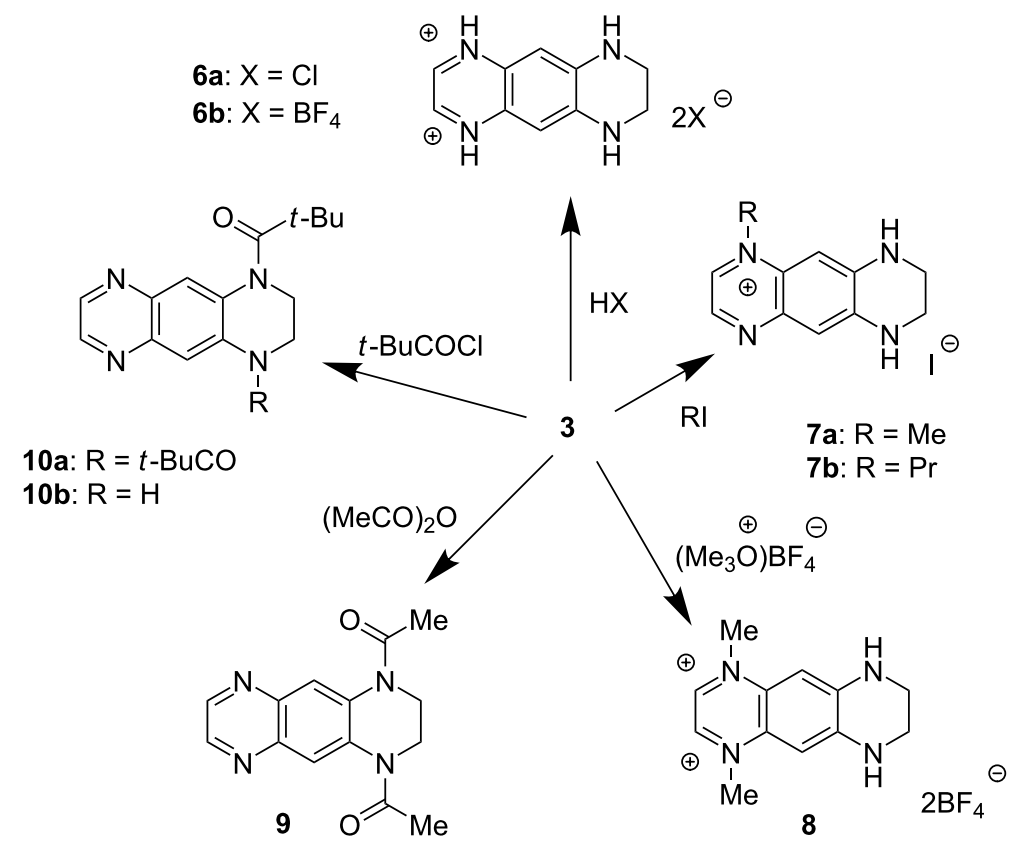

Scheme 2: Protonation, alkylation and acylation of 3. 


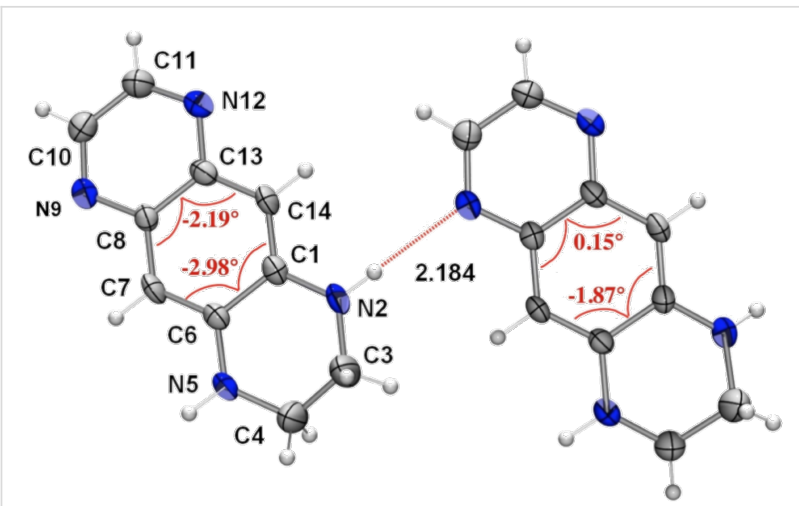

Figure 2: The ORTEP view of 3. Torsion angles within the benzene ring are given in red.

tron donating ethylenediamino moiety (D) toward the electron accepting ethylenediimino (A) moiety as shown by the narrow range of the $\mathrm{C}-\mathrm{N}$ averaged distances from 1.363 to $1.367 \AA$ (Table 1). The $\mathrm{C} 1-\mathrm{C} 2$ and $\mathrm{C} 4-\mathrm{C} 5$ distances vary between 1.447 and $1.421 \AA$, respectively, indicating poor conjugation through these bonds, as a result of a partial loss of the aromaticity of the central benzene ring. This feature is confirmed also by the deviation of the benzene ring planarity as shown in Figure 1: the torsion angles C7-C6-C1-C14 and C7-C8-C13-C14 exceed 2 degrees. The planarity distortion cannot be attributed solely to the intramolecular interaction effects, as our calculations [22] using the B3LYP/6-311+G(2d,p)//B3LYP/6-311+G(2d,p) model chemistry also reproduce the distortion, albeit to a smaller extent: 1.07 and 0.2 degrees. The frequency calculation reproduces the experimental IR spectrum reasonably well (Supporting Information File 1, Figure S1).

The X-ray structure determination of $\mathbf{6 a}$ confirms that the protonation occurs at 5,8-positions (Figure 3). The distances between both $>\mathrm{N}-\mathrm{H}$ and $=\mathrm{N}-\mathrm{H}$ groups from the chlorine anions are shortened (2.410 and $2.194 \AA$, respectively, Figure 2). Examination of the bond distances within the N2-C1-C14-C13-N12 and N5-C6-C7-C8-N9 atom chains of 6a reveals almost full delocalization of the positive charge along the both conjugated moieties (Table 1). The bonds of C1-C6 (1.469 $)$ ) and C8-C13 (1.441 $⿱$ ) are also elongated, indicating further loss of aromaticity within the dication. The planarity distortion is smaller than observed in $\mathbf{3}$, judging by the torsion angles C7-C6-C1-C14 and C7-C8-C13-C14 (Figure 3). At the same time, the geometry optimized structure of $6 \mathbf{a}$ exhibits much greater torsion angles of 6.23 and 2.28 degrees.

The X-ray structure analysis of 7a confirms that the methylation occurs at the $\mathrm{N} 4$ atom to form the respective cation (Figure 4). Examination of the bond distances revealed a signif-

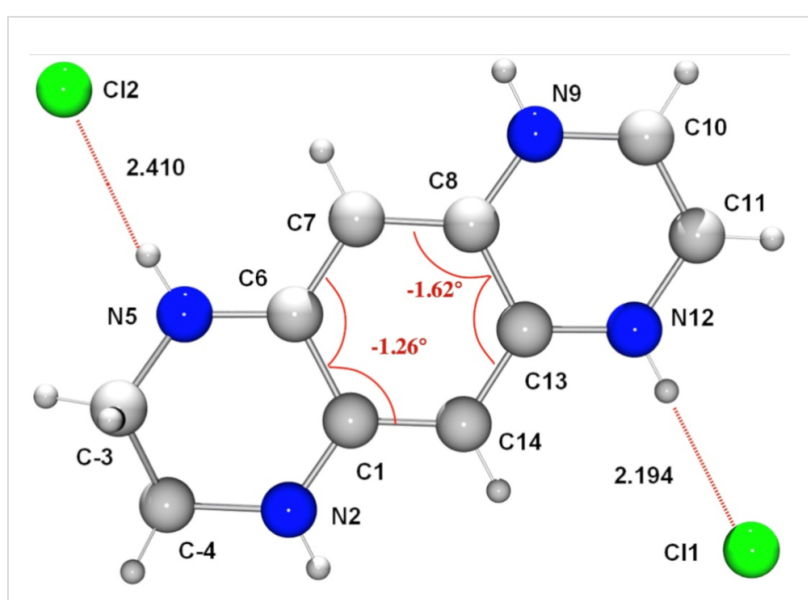

Figure 3: The ORTEP view of 6 a. Torsion angles within the benzene ring are given in red.

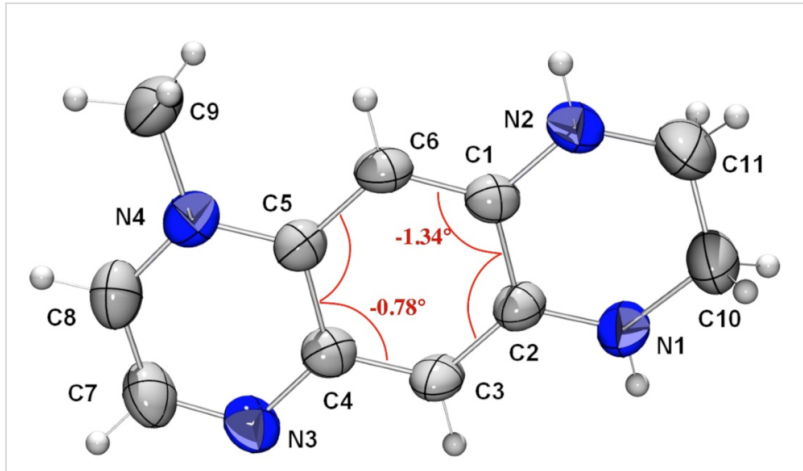

Figure 4: The ORTEP view of 7a (the iodine counter anion has been omitted for clarity). Torsion angles within the benzene ring are given in red.

icant degree of the positive charge delocalization predominantly over the N2-C1-C6-C5-N4 moiety of the molecule. The torsion angles within the benzene ring are smaller than calculated $\left(1.09^{\circ}\right.$ and $1.95^{\circ}$, respectively) and those of found in $\mathbf{3}$ and 6 a.

The above observations suggest that the degree of aromaticity of quinoxaline derivative $\mathbf{3}$ decreases compared to aromatic and planar $1[23,24]$ because of the presence of the amino groups that give rise to intramolecular charge transfer. This effect is even stronger in $6 \mathbf{a}$ and $7 \mathbf{a}$ because of delocalization of the positive charge. The equilibrium geometries of $\mathbf{3}, \mathbf{6 a}$ and 7a obtained by calculations are in good agreement with the X-ray structural data (Table 1). The geometry optimized structures confirm that the bond lengths equalization and the aromaticity loss observed in the X-ray structures stem from the intramolecular charge transfer from the electron-donating ethylenediamino moiety toward the electron-accepting ethylenediimino moiety in $\mathbf{3}$ and delocalization of the positive charges in $\mathbf{6 a}$ and 
7a (Scheme 3), and are not artifacts arising from the strong intermolecular interactions within the crystals. Losing aromaticity, the benzene ring is becoming less rigid and the molecules can become more or less planar to adopt the constrains of the molecular packing. Thus, the structures of salts 6a and 7a resemble more those of cyanine dyes and the structure of $\mathbf{3}$ those of merocyanines.

3<smiles>C1=[N+]c2cc3[nH+]ccnc3cc2[NH+]=C1</smiles><smiles>CC1=CC2=CC3=NCCNC(=CC3=C1)NC=CN2</smiles>

$7 a$<smiles>C[n+]1ccnc2cc3c(cc21)NCCN3</smiles>

Scheme 3: Charge transfer and delocalization within $\mathbf{3}$ and its diprotonated (6a) and monomethylated (7a) derivatives.

The protonation positions of $\mathbf{3}$ are correctly predicted by the calculations. For instance, the energy difference between the dication 6 and a hypothetic dication with protonated amino groups is $51 \mathrm{kcal} / \mathrm{mol}$ in favor of $\mathbf{6}$.

\section{UV-vis absorption spectra}

In solution, $\mathbf{3}$ is characterized by a strong absorption band, at $402 \mathrm{~nm}$ (toluene), $406 \mathrm{~nm}$ (acetone), $413 \mathrm{~nm}$ (water) and $422 \mathrm{~nm}$ (ethanol) $(\varepsilon \approx 20,000)$. Whereas a $5 \mathrm{~nm}$ shift between the absorption maximum in toluene and acetone evidences the presence of slight positive solvatochromism, the band shapes in water and ethanol are irregular and reflect rather specific interaction with these solvents. The shoulder extending from 450 till $540 \mathrm{~nm}$ observed in water disappears upon addition of a base $(\mathrm{KOH})$ and indicates partial protonation (Figure 5). In non-polar solvents this band shows features of weak vibronic splitting. Minimum three Pekarian functions are needed to reproduce the band shape in toluene indicating that at least three electronic transitions are involved (Supporting Information File 1, Figure S2)

Protonation of $\mathbf{3}$ with acids ( $\mathrm{HCl}$ or $\mathrm{HBF}_{4}$ in ethanol) occurs in two separate steps (Figure 6) and the formation of the dication requires an excess of the acid. The dropwise addition of the acid to the solution of $\mathbf{3}$ gives rise to the appearance of an absorp-

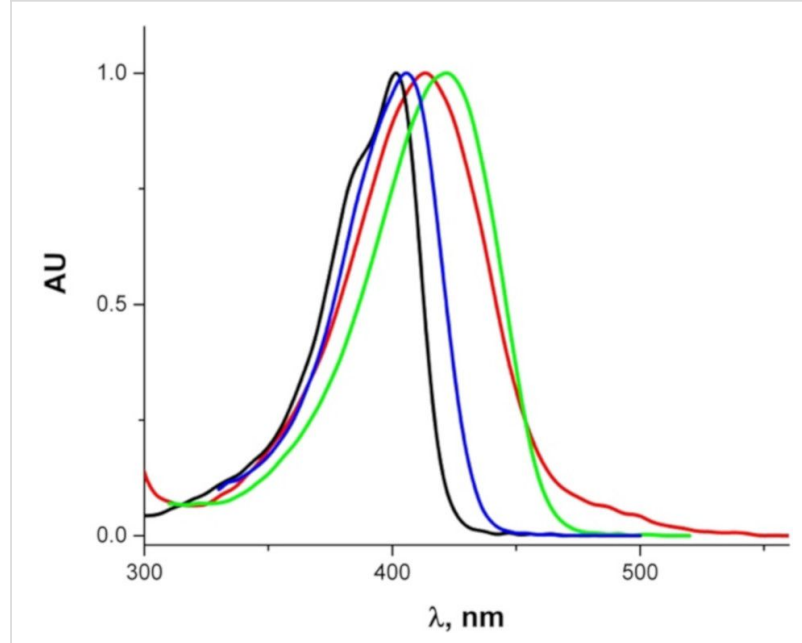

Figure 5: Normalized absorption spectra of $\mathbf{3}$ in: toluene (black), acetone (blue), ethanol (green), water (red)

tion band at $467 \mathrm{~nm}$ corresponding to the monoprotonated species (blue curves, IBP1). Further addition of the acid leads to the appearance of another absorption band at $482 \mathrm{~nm}$ corresponding to the bis-protonated species (red curves, ABP2). The protonated species of $\mathbf{3}$ are not fluorescent. Minimum two Pekarian functions are needed to reproduce the band shape of the salts $\mathbf{6}$ in ethanol indicating that at least two electronic transitions are involved (Supporting Information File 1, Figure S3).

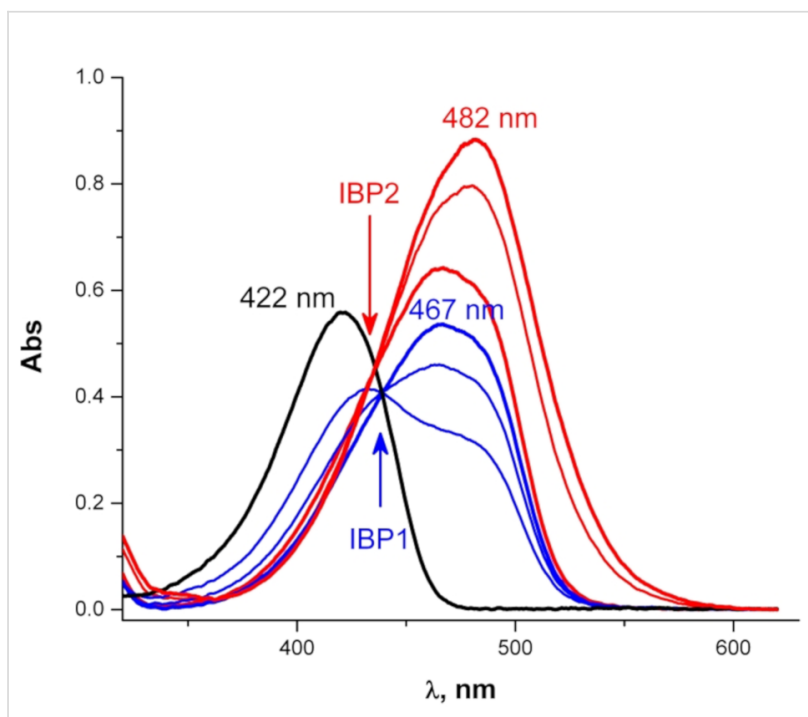

Figure 6: Protonation of 3 in ethanol. Two isosbestic points (IBP) are indicated by arrows.

TD DFT calculations interprets the longest wavelength absorption bands of $\mathbf{3}$ and $\mathbf{6}$ to be predominantly the charge transfer type HOMO -> LUMO transitions (Supporting Information File 1, Tables S1 and S2). 
The easiness of protonation and stability of salts 6 evidenced the behavior of THTAA (3) as a strong base. Indeed, our DFT calculations of the proton affinity of THTAA (3) produced $\Delta H^{298}=235.9 \mathrm{kcal} / \mathrm{mol}$. For comparison, we calculated the proton affinities of quinoline: 217.0 and 4-dimethylaminopyridine: $240.1 \mathrm{kcal} / \mathrm{mol}$ at the same level of theory (the experimental values for these two derivatives are 214.4 and $235.7 \mathrm{kcal} / \mathrm{mol}$, respectively [25]). Thus, the basicity of $\mathbf{3}$ is close to that of 4-dimethylaminopyridine.

The absorption spectra of 7a and $\mathbf{8}$ (Figure 7) resemble those of the mono- and diprotonated species of $\mathbf{3}$ (Figure 5), respectively.

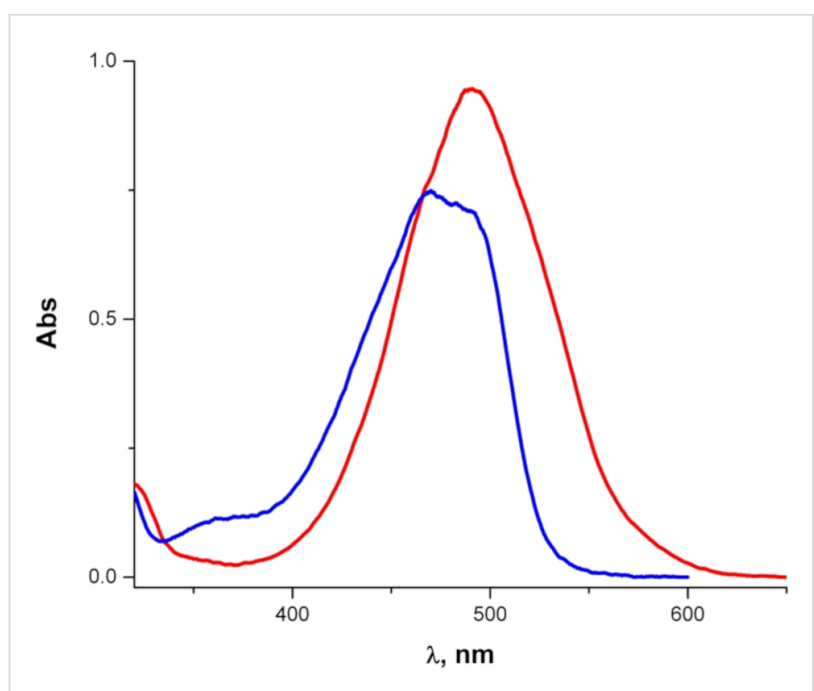

Figure 7: Absorption spectra of 7a (blue) and 8 (red) in ethanol.

The absorption spectra of the acylated derivatives $\mathbf{1 0 a}$ and $\mathbf{1 0 b}$ are shown in Figure 8. Whereas the mono-acylated derivative 10b, which retains one electron-donating substituent $(\mathrm{N}-\mathrm{H})$, absorbs at about the same wavelength as $\mathbf{3}$ and exhibits a weak positive solvatochromic shift of about $7 \mathrm{~nm}$, absorption of bisacylated derivative 10a is strongly blue shifted and shows no solvatochromism.

As noted in [5], both $\mathbf{3}$ and $\mathbf{5}$ undergo rapid photoreactions in solution in the presence of moisture. The photochemistry of both compounds is currently under investigation in our labs.

\section{Crystal structures}

Numerous short intermolecular contacts are revealed upon inspection the crystal lattice of $\mathbf{3}, \mathbf{6 a}$ and $7 \mathbf{a}$. There are two independent molecules of $\mathbf{3}$ in the unit cell with slightly different bond lengths. The dominant motive seen for $\mathbf{3}$ in the solid state is the formation of infinite chains based on $\mathrm{N}-\mathrm{H} \cdots \mathrm{N}=\mathrm{C}$ hydrogen bonds (N...N distances 3.011-3.047 A, Figure 9).

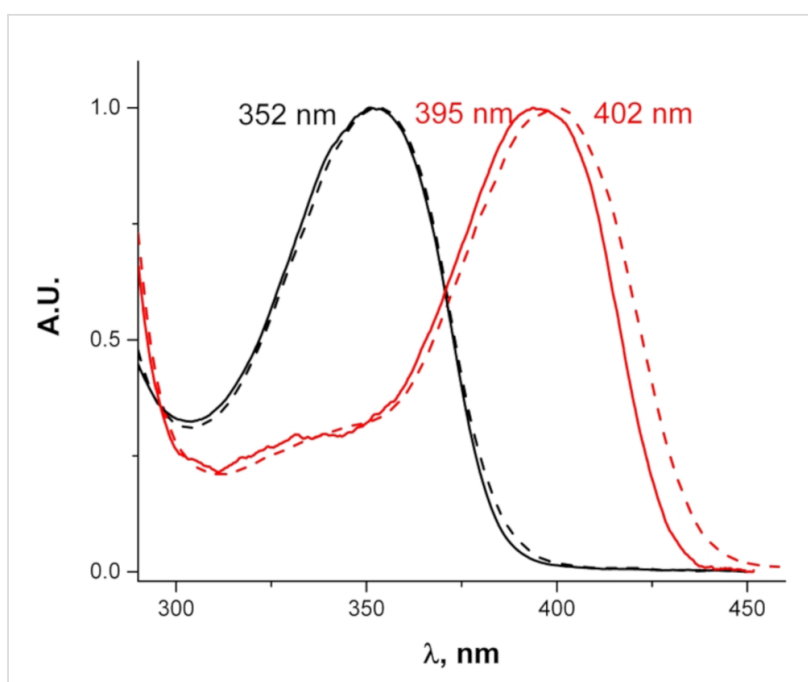

Figure 8: Absorption spectra of 10a (black), 10b (red). Solid curves: in toluene, dashed curves: in acetone.

The crystal lattice of $\mathbf{6 a}$ (Figure 10) also exhibits the presence of the infinite chains $>\mathrm{N}-\mathrm{H} \cdots \mathrm{Cl}^{-} \cdots \mathrm{H}-\mathrm{N}^{+}$: the $\mathrm{Cl}^{-} \cdots \mathrm{N}$ and $\mathrm{Cl}^{-} \ldots \mathrm{N}^{+}$distances being 3.184 and $3.042 \AA$, respectively. These interactions, as well as intramolecular charge transfer from the electron-donating ethylenediamino moiety to the electronaccepting ethylenediimino moiety give rise to a certain degree of the single and double bond lengths equalization. Thus, $6 \mathbf{a}$ forms a 2D supramolecular network involving the chloride anion $\mathrm{Cl1}$ as an intermolecular connector between the molecules. Each anion interacts with the two $\mathrm{N}-\mathrm{H}$ protons of the associated dications (Figure 10).

In spite of the asymmetrical structure, the X-ray structure of 7a exhibits the same trend: infinite chains of the $\mathrm{N}-\mathrm{H} \cdots \mathrm{N}=\mathrm{C}$ shortened distances $(\mathrm{N}(2) \cdots \mathrm{N}(3)$ distance $3.047 \AA$, (Figure 11). The iodine anions are not involved in the intermolecular interactions.

\section{Conclusion}

Unlike previously described, 1,2,3,4-tetrahydro-1,4,5,8tetraazaanthracene $(3)$ is a thermally stable compound and can be sublimed at about $300{ }^{\circ} \mathrm{C}$ without decomposition. Sublimation is required for its complete purification. The crystal structures of $\mathbf{3}$ and its derivatives exhibit the formation of infinite chains binding molecules in the side-to-side manner even in the case when a substituent is present at one of the nitrogen atoms. This molecule can be easily modified at either ethylenediamino or ethylenediimino moiety and can thus serve as an attractive precursor for crystal design and creation of supramolecular assemblies. Of special interest is that the quinoxaline moiety of THTAA (3) and its derivatives are losing their aromaticity owing to the charge transfer from the electron-donating moiety 


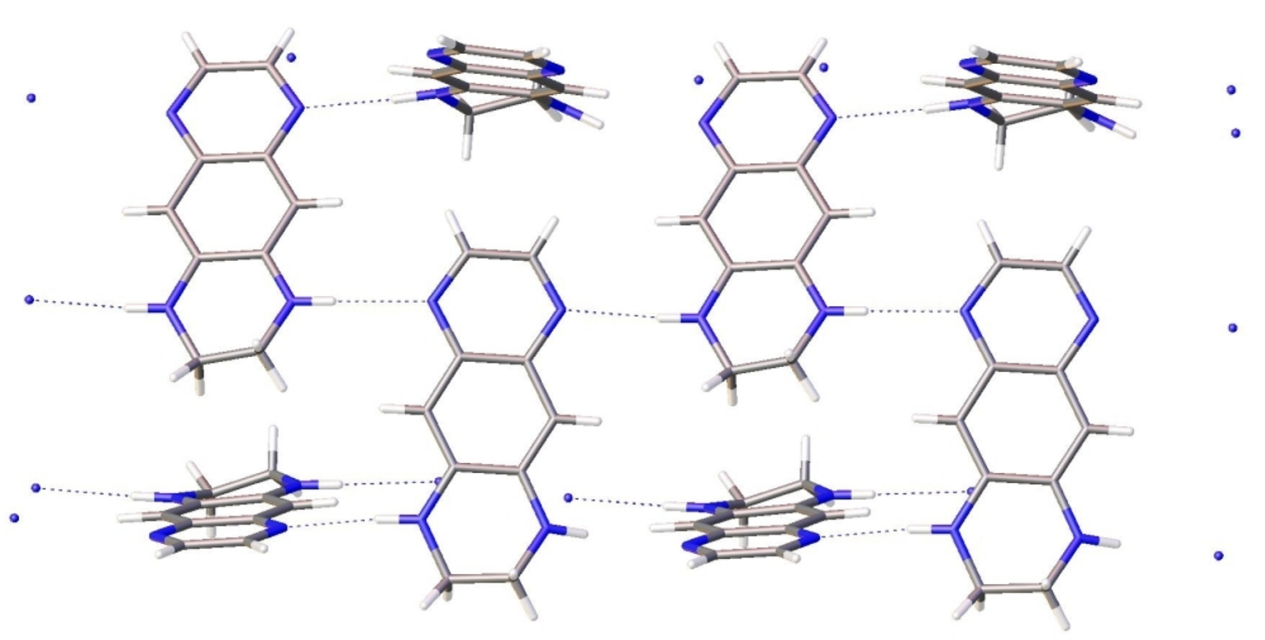

Figure 9: View of the supramolecular array generated by 3 in the solid state. Color coding: nitrogen, blue; carbon, grey.

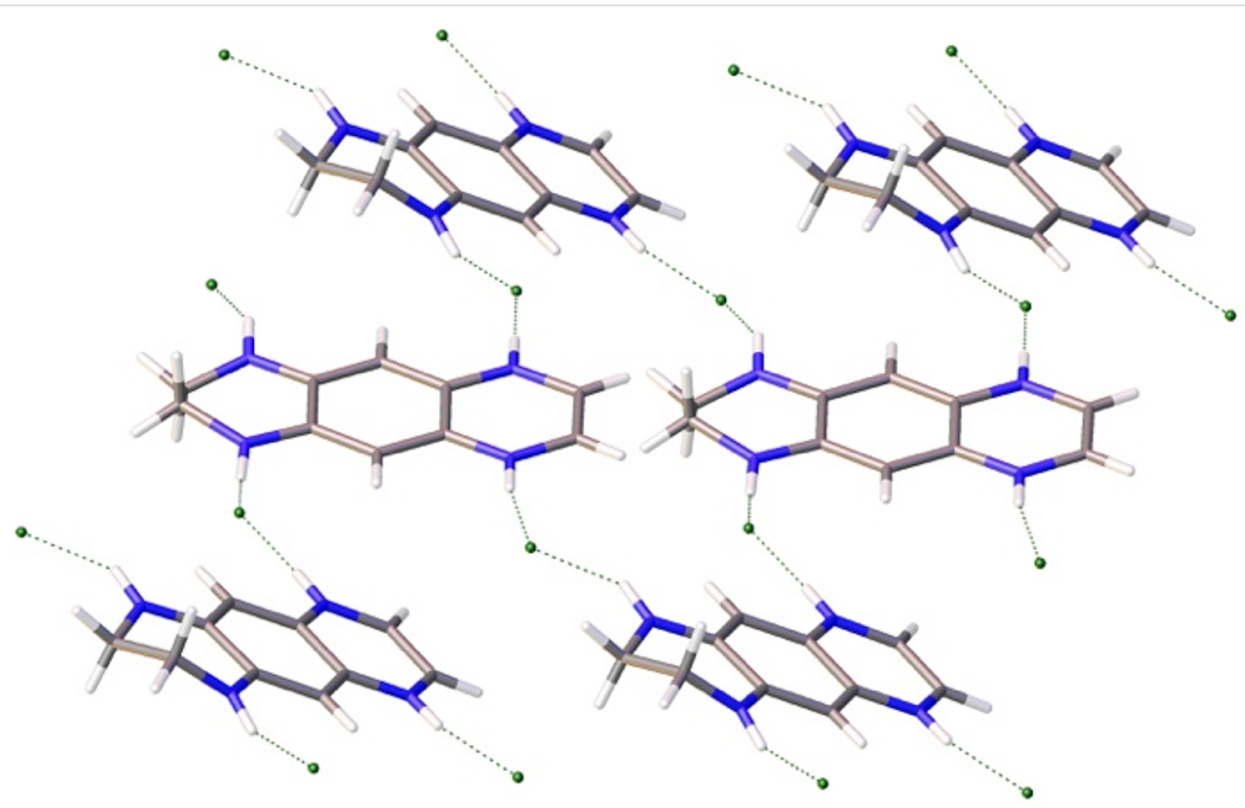

Figure 10: View of the supramolecular array generated by $6 a$ in the solid state. Color coding: nitrogen, blue; carbon, grey, chloride, green.

towards the electron-accepting moieties via the benzene ring. In solution both derivatives $\mathbf{3}$ and $\mathbf{5}$ are light sensitive. Photochemical reactions of THTAA (3) and TAA (5) are currently under investigation in our labs.

\section{Experimental}

Reagents and starting materials were used as received without further purification from Alfa Aesar and Aldrich. Analytical thin-layer chromatography (TLC) was done on Merck $60 \mathrm{~F}_{254}$ silica gel plates from Macherey-Nagel. Detection of TLC components was accomplished using a 254/366 nm UV lamp. Column liquid chromatography was carried out on Merck silica gel 60 (70-230 mesh). Melting points were determined on a Büchi 510 apparatus in open glass capillaries and are uncorrected. The IR spectra were recorded with an Agilent 360FTIR instrument. The UV-vis absorption spectra were recorded with Ocean Optics USB 4000 and JASCO V-660 spectrophotometers. ${ }^{1} \mathrm{H}$ and ${ }^{13} \mathrm{C}$ NMR spectra were recorded with a JEOL JNM-ECS400 spectrometer at 399.78 and $100.53 \mathrm{MHz}$, respectively. Chemical shifts are given in ppm downfield from tetramethylsilane and coupling constants $(J)$ in Hertz. Elemental analysis was made using a Thermo Finnigan EA 1112 instrument. HRMS was made at the Spectropole (http://frchimie.univ-amu.fr/spectropole/). 


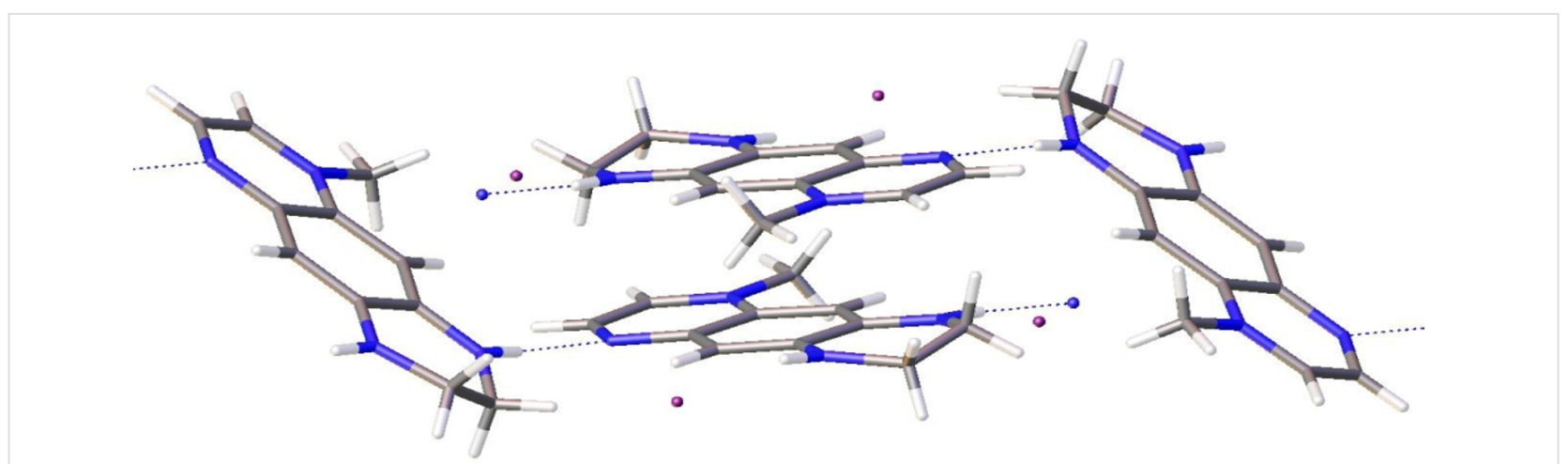

Figure 11: View of the supramolecular array generated by $7 \mathbf{a}$ in the solid state. Color coding: nitrogen, blue; carbon, grey; iodine, violet.

The X-ray crystallography data were collected on a BrukerNonius KappaCCD diffractometer with CCD detector using Mo $\mathrm{K} \alpha$ radiation, $\lambda=0.71073 \AA$ A. Crystallographic data (excluding structure factors) for the structures in this paper have been deposited with the Cambridge Crystallographic Data Centre as supplementary publication: 3 CCDC 1912951, 6a CCDC 1912953, 7a CCDC 1912952.

Quantum mechanical calculations were done with Gaussian 09 software [22] using B3LYP/6-311+G(2d,p) model chemistry. All energies include ZPE correction. 6 states were included in the TD B3LYP calculations.

1,2,3,4-Tetrahydropyrazino[2,3-g]quinoxaline (3, THTAA): THTAA was prepared as described in [8] from 4 . The brown precipitate of the crude product ( $50 \%$ yield) was extracted with hot butyl acetate, from which $\mathbf{3}$ precipitated as brownish yellow crystals in 50\% yield. The bright yellow crystals of $\mathbf{3}$ used for recording the UV-vis absorption spectra and X-ray structure determination can be obtained only by sublimation. ${ }^{1} \mathrm{H}$ NMR (DMSO- $d_{6}$ ) $\delta 3.28$ (s, 4H), 6.67 (br s, 2H), 6.68 (s, 2H), 8.17 $(\mathrm{s}, 2 \mathrm{H}) ;{ }^{13} \mathrm{C} \mathrm{NMR}\left(\mathrm{DMF}-d_{7}\right) \delta 39.84\left(\mathrm{CH}_{2}\right), 104.88(\mathrm{CH})$, $139.64(\mathrm{CH}), 140.29(\mathrm{C}), 140.33(\mathrm{C})$. IR (sublimed solid sample) $v, \mathrm{~cm}^{-1}: 3229-2838(\mathrm{w}), 1507$ (s), 1340, 1315, $1218,844,810,487$ (see also Supporting Information File 1, Figure S1).

\section{1,2,3,4-Tetrahydropyrazino[2,3-g]quinoxaline-6,9-diium}

dichloride (6a): To a suspension of 1,2,3,4-tetrahydropyrazino[2,3- $g$ ]quinoxaline $(3,500 \mathrm{mg}, 2.68 \mathrm{mmol})$ in ethyl acetate $(50 \mathrm{~mL})$ was added dropwise via syringe an solution of hydrogen chloride in ethanol $(1.25 \mathrm{M}, 13.4 \mathrm{mmol}, 10.7 \mathrm{~mL})$ at $0{ }^{\circ} \mathrm{C}$. After stirring for 2 hours at room temperature, the red precipitate was isolated by filtration in $85 \%$ yield $(582 \mathrm{mg}) .{ }^{1} \mathrm{H}$ NMR $\left(\mathrm{DMSO}-d_{6}\right) \delta 3.42$ (s, 4H), 6.93 (s, 2H), 8.25 (br s, 2H), 8.35 (s, $2 \mathrm{H}$ ); anal. calcd for $\mathrm{C}_{10} \mathrm{H}_{12} \mathrm{~N}_{4} \mathrm{Cl}_{2}: \mathrm{C}, 46.35 ; \mathrm{H}, 4.67 ; \mathrm{N}, 21.62$; found: C, 46.20; H, 4.62; N, 21.35 .
1,2,3,4-Tetrahydropyrazino [2,3-g]quinoxaline-6,9-diium bis(tetrafluoroborate) (6b): To a suspension of 1,2,3,4tetrahydropyrazino[2,3-g]quinoxaline $(3,500 \mathrm{mg}, 2.68 \mathrm{mmol})$ in ethyl acetate $(50 \mathrm{~mL})$ was added dropwise via syringe a commercial solution of tetrafluoroboric acid in diethyl ether (51-57\%, $13.4 \mathrm{mmol}, 1.7 \mathrm{~mL}$ ) at $0{ }^{\circ} \mathrm{C}$. After stirring for 2 hours at room temperature, the red precipitate was isolated by filtration in $78 \%$ yield $\left(756 \mathrm{mg}\right.$ ). ${ }^{1} \mathrm{H}$ NMR (acetone- $\left.d_{6}\right) \delta 3.53$ (s, 4H), 6.92 (s, 2H), 7.88 (br s, 2H), 8.33 (s, 2H); anal. calcd. for $\mathrm{C}_{10} \mathrm{H}_{12} \mathrm{~N}_{4} \cdot 2 \mathrm{BF}_{4}$ : C, 33.19; H, 3.34; N, 15.48; found: C, 33.26; $\mathrm{H}, 3.22 ; \mathrm{N}, 15.91$.

6-Methyl-1,2,3,4-tetrahydropyrazino[2,3-g]quinoxalinium iodide (7a): A solution of 1,2,3,4-tetrahydropyrazino[2,3g]quinoxaline (3), $100 \mathrm{mg}, 0.537 \mathrm{mmol}$ ), iodomethane $(0.33 \mathrm{~mL}, 762 \mathrm{mg}, 5.37 \mathrm{mmol})$ in acetonitrile $(7 \mathrm{~mL})$ was heated in a sealed ampulla at $80{ }^{\circ} \mathrm{C}$ for 2 days. After removing the solvent in vacuo, the residue was taken up in ethyl acetate ( $3 \mathrm{~mL}$ ). The obtained precipitate is then isolated by filtration and washed with ethyl acetate affording the titled product as dark red solid in $90 \%$ yield $(158 \mathrm{mg}) ;{ }^{1} \mathrm{H}$ NMR (DMSO- $\left.d_{6}\right) \delta$ $3.42\left(\mathrm{~m}, 2 \mathrm{H}, \mathrm{CH}_{2}\right), 3.53\left(\mathrm{~m}, 2 \mathrm{H}, \mathrm{CH}_{2}\right), 4.17\left(\mathrm{~s}, 3 \mathrm{H}, \mathrm{CH}_{3}\right), 6.78$ (s, 1H), $6.95(\mathrm{~s}, 1 \mathrm{H}), 7.84(\mathrm{~s}, 1 \mathrm{H}, \mathrm{NH}), 8.37(\mathrm{~d}, J=3.5 \mathrm{~Hz}, 1 \mathrm{H})$, $8.49(\mathrm{~d}, J=3.5 \mathrm{~Hz}, 1 \mathrm{H}), 8.79(\mathrm{~s}, 1 \mathrm{H}, \mathrm{NH})$; anal. calcd for $\mathrm{C}_{11} \mathrm{H}_{13} \mathrm{~N}_{4} \mathrm{I} \cdot 1 / 2 \mathrm{H}_{2} \mathrm{O}: \mathrm{C}, 39.2 ; \mathrm{H}, 4.2 ; \mathrm{N}, 16.6$; found: $\mathrm{C}, 39.2 ; \mathrm{H}$, $3.8 ; \mathrm{N}, 16.6$.

\section{6-Propyl-1,2,3,4-tetrahydropyrazino[2,3-g]quinoxalinium} iodide (7b): A solution of 1,2,3,4-tetrahydropyrazino[2,3g]quinoxaline $(3,100 \mathrm{mg}, 0.537 \mathrm{mmol})$, iodopropane $(0.53 \mathrm{~mL}, 912 \mathrm{mg}, 5.37 \mathrm{mmol})$ in acetonitrile $(7 \mathrm{~mL})$ was heated at $80^{\circ} \mathrm{C}$ for 2 days. After removing the solvent in vacuo, the residue was taken up in ethyl acetate $(3 \mathrm{~mL})$. The obtained precipitate is then isolated by filtration and washed with ethyl acetate affording the product as dark red solid in $92 \%$ yield $(176 \mathrm{mg}) .{ }^{1} \mathrm{H}$ NMR (DMSO- $\left.d_{6}\right) \delta 0.93(\mathrm{t}, J=7.3 \mathrm{~Hz}, 3 \mathrm{H})$, 1.91 (sext, $J=7.3 \mathrm{~Hz}, 2 \mathrm{H}), 3.40\left(\mathrm{~m}, 2 \mathrm{H}, \mathrm{NCH}_{2}\right), 3.52(\mathrm{~m}, 2 \mathrm{H}$, 
$\mathrm{NCH}_{2}$ ), 4,50 (t, $\left.J=7.3 \mathrm{~Hz}, 2 \mathrm{H}\right), 5,24$ (br s, 1H, NH), 6.92 (s, $1 \mathrm{H}), 6.95(\mathrm{~s}, 1 \mathrm{H}), 7,82(\mathrm{br} \mathrm{s}, 1 \mathrm{H}), 8.36(\mathrm{~d}, J=3.6 \mathrm{~Hz}, 1 \mathrm{H})$, $8.49(\mathrm{~d}, J=3.6 \mathrm{~Hz}, 1 \mathrm{H}), 8.67(\mathrm{~s}, 1 \mathrm{H})$; anal. calcd for $\mathrm{C}_{13} \mathrm{H}_{17} \mathrm{~N}_{4} \mathrm{I} \cdot \mathrm{H}_{2} \mathrm{O}$ : C, 41.7; H, 5.1; N, 14.96; found: $\mathrm{C}, 42.4 ; \mathrm{H}$, 4.2; N, 14.1 .

6,9-Dimethyl-1,2,3,4-tetrahydropyrazino[2,3-g]quinoxalinium bis(tetrafluoroborate) (8): 1,2,3,4-Tetrahydropyrazino[2,3-g]quinoxaline $(100 \mathrm{mg}, 0.537 \mathrm{mmol})$ and trimethyloxonium tetrafluoroborate $(198 \mathrm{mg}, 1.342 \mathrm{mmol}$, 2.5 equiv) in $12 \mathrm{~mL}$ of dry 1,2-dichloroethane were refluxed for $5 \mathrm{~h}$. The red precipitate was filtered and washed with pentane. Recrystallisation from ethanol gave red prisms (157 mg, 75\%). ${ }^{1} \mathrm{H}$ NMR (DMSO- $d_{6}$ ) $\delta 3.71(\mathrm{~s}, 4 \mathrm{H}), 4.18$ (s, $6 \mathrm{H}), 6.91(\mathrm{~s}, 2 \mathrm{H}), 8.45(\mathrm{~s}, 2 \mathrm{H}), 10.15(\mathrm{~s}, 2 \mathrm{H}) ;{ }^{13} \mathrm{C} \mathrm{NMR}$ $\left(\mathrm{DMSO}_{6} \mathrm{~d}_{6}\right) \delta 38.24\left(\mathrm{CH}_{2}\right), 44.07\left(\mathrm{CH}_{3}\right), 93.54(\mathrm{CH}), 127.79$ $(\mathrm{CH}), 136.85,146.58 ;{ }^{19} \mathrm{~F}$ NMR (DMSO- $\left.d_{6}\right) \delta 148$; HRMS (ESIMS) $\mathrm{m} / \mathrm{z}:\left[\mathrm{M}^{2+}\right.$ ]; calcd. for $\mathrm{C}_{12} \mathrm{H}_{16} \mathrm{~N}_{4}{ }^{2+} 216.1364$ 108.0682; found, 108.0683 .

1,4-Diacetyl)-1,2,3,4-tetrahydropyrazino[2,3-g]quinoxaline (9): 1,2,3,4-Tetrahydropyrazino[2,3-g]quinoxaline (3,500 mg, $2.68 \mathrm{mmol}$ ) was added to $20 \mathrm{~mL}$ of acetic anhydride and the mixture was stirred at reflux for $48 \mathrm{~h}$. After cooling, the excess of acetic anhydride was evaporated under reduced pressure. The residue was triturated with dichloromethane $(20 \mathrm{~mL})$ and $\mathrm{H}_{2} \mathrm{O}$ $(20 \mathrm{~mL})$. The aqueous layer was neutralized by adding solid sodium carbonate and extracted with dichloromethane $(2 \times 20 \mathrm{~mL})$. The extracts were dried over magnesium sulfate and concentrated in vacuo. The residue was purified by column chromatography on silica gel using $\mathrm{CH}_{2} \mathrm{Cl}_{2} / \mathrm{AcOEt} / \mathrm{MeOH}$ (8:2:1) as eluent, to give the titled product $(696 \mathrm{mg}, 96 \%)$ as colorless solid. Mp: $232{ }^{\circ} \mathrm{C}\left(244{ }^{\circ} \mathrm{C}[8]\right) ;{ }^{1} \mathrm{H}$ NMR $\left(\mathrm{CDCl}_{3}\right) \delta$ 2.37 (s, 6H), 4.05 (s, 4H), 8.06 (br s, 2H), 8.79 (s, 2H); ${ }^{13} \mathrm{C} \mathrm{NMR}\left(\mathrm{CDCl}_{3}\right) \delta 22.91,44.53,122.98,136.17,140.59$, 144.96, 169.49; anal. calcd for $\mathrm{C}_{14} \mathrm{H}_{14} \mathrm{~N}_{4} \mathrm{O}_{2}$ : C, 62.21; H, 5.22; N, 20.73; found: C, 62.31; H, 5.13; N, 20.60.

1,4-Bis(2,2-dimethylpropanoyl)-1,2,3,4-tetrahydropyrazino[2,3-g]quinoxaline (10a): To a mixture of 1,2,3,4tetrahydropyrazino[2,3-g] quinoxaline $(\mathbf{3}, 500 \mathrm{mg}, 2.68 \mathrm{mmol})$, $\mathrm{N}, \mathrm{N}$-diisopropylethylamine $(2.33 \mathrm{~mL}, 13.42 \mathrm{mmol})$ in acetonitrile $(35 \mathrm{~mL})$ was added drop wise via syringe trimethylacetyl chloride ( $1.64 \mathrm{~mL}, 1.62 \mathrm{~g}, 13.42 \mathrm{mmol}$ ). The resulting mixture was stirred at $80{ }^{\circ} \mathrm{C}$ for 3 days. After cooling, the solvents were evaporated in vacuo and the residue was dissolved in dichloromethane $(50 \mathrm{~mL})$. The organic layer was washed with an aqueous sodium hydroxide $(1 \mathrm{M}, 2 \times 5 \mathrm{~mL})$, then with water $(10 \mathrm{~mL})$, dried over magnesium sulfate, evaporated. The crude product was purified by column chromatography on silica gel using $\mathrm{CH}_{2} \mathrm{Cl}_{2} / \mathrm{AcOEt}$ (4:1) to furnish the product in $87 \%$ yield
(828 mg) as a yellow solid. Mp: $232{ }^{\circ} \mathrm{C} ;{ }^{1} \mathrm{H}$ NMR (DMSO- $d_{6}$ ) $\delta 1.24(\mathrm{~s}, 18 \mathrm{H}), 4.03(\mathrm{~s}, 4 \mathrm{H}), 8.04(\mathrm{~s}, 2 \mathrm{H}), 8.86(\mathrm{~s}, 2 \mathrm{H})$; ${ }^{13} \mathrm{C}$ NMR (DMSO- $\left.d_{6}\right) \delta 28.41,40.19,46.86,124.16,138.17$, 139.79, 145.48, 177.59; HRMS (ESIMS) $\mathrm{m} / \mathrm{z}$ : $[\mathrm{M}+\mathrm{H}]^{+}$calcd. for $\mathrm{C}_{20} \mathrm{H}_{26} \mathrm{~N}_{4} \mathrm{O}_{2}{ }^{+}$, 355.2129; found, 355.2130.

1-(2,2-Dimethylpropanoyl)-1,2,3,4-tetrahydropyrazino[2,3g]quinoxaline (10b): To a mixture of 1,2,3,4-tetrahydropyrazino[2,3-g]quinoxaline $(3,500 \mathrm{mg}, 2.68 \mathrm{mmol})$, triethylamine $(0.6 \mathrm{~mL}, 0.48 \mathrm{~g}, 4.56 \mathrm{mmol})$ in acetonitrile $(250 \mathrm{~mL})$ was added dropwise via syringe trimethylacetyl chloride $(0.49 \mathrm{~mL}$, $0.48 \mathrm{~g}, 4 \mathrm{mmol})$. The resulting mixture was stirred the mixture was stirred at $80{ }^{\circ} \mathrm{C}$ for 12 hours. After cooling, the solvents were evaporated in vacuo and the residue was dissolved in dichloromethane $(50 \mathrm{~mL})$. The organic layer was washed with a aqueous sodium hydroxide $(1 \mathrm{M}, 2 \times 5 \mathrm{~mL})$, then with water $(10 \mathrm{~mL})$, dried over magnesium sulfate, and evaporated. The crude product was purified by column chromatography on silica gel using cyclohexane/AcOEt (3:7) to furnish the titled product in $48 \%$ yield $\left(348 \mathrm{mg}\right.$ ) as a yellow solid. ${ }^{1} \mathrm{H}$ NMR $\left(\mathrm{CDCl}_{3}\right) \delta 1.38(\mathrm{~s}, 9 \mathrm{H}), 3.67(\mathrm{t}, J=5.1 \mathrm{~Hz}, 2 \mathrm{H}),, 3.95(\mathrm{t}, J=$ $5.1 \mathrm{~Hz}, 2 \mathrm{H}), 4.94(\mathrm{~s}, 1 \mathrm{H}, \mathrm{NH}), 7.09(\mathrm{~s}, 1 \mathrm{H}), 8.00(\mathrm{~s}, 1 \mathrm{H}), 8.52$ $(\mathrm{d}, \mathrm{J}=2 \mathrm{~Hz}, 1 \mathrm{H}), 8.55(\mathrm{~d}, J=2 \mathrm{~Hz}, 1 \mathrm{H})$; anal. calcd for $\mathrm{C}_{15} \mathrm{H}_{18} \mathrm{~N}_{4} \mathrm{O}: \mathrm{C}, 66.7 ; \mathrm{H}, 6.7$;, 20.7 ; found: C, 67.0; H, 7.1; N, 20.2 .

\section{Supporting Information}

\section{Supporting Information File 1}

Experimental and calculated IR spectra of 3, UV-vis absorption spectra of $\mathbf{3}$ in toluene and its fitting with Pekarian function, NMR spectra.

[https://www.beilstein-journals.org/bjoc/content/ supplementary/1860-5397-15-203-S1.pdf]

\section{Acknowledgements}

This work was supported by the Centre National de la Recherche Scientifique, the Ministère de la Recherche et des Nouvelles Technologies and computing facilities of the CRCMM, 'Centre Régional de Compétences en Modélisation Moléculaire de Marseille'. We also thank M. Giorgi (Spectropole, Marseille) for the X-ray analyses.

\section{ORCID ${ }^{\circledR}$ iDs}

Vladimir Khodorkovsky - https://orcid.org/0000-0001-9091-6837

\section{References}

1. Simpson, J. C. E. Condensed Pyridazine and Pyrazine Rings: Cinnolines, Phthalazines, and Quinoxalines; John Wiley \& Sons, Inc.: Hoboken, NJ, U.S.A., 1953. 
2. Cheeseman, G. W. H.; Cookson, R. F. Condensed Pyrazines; Chemistry of Heterocyclic Compounds: A Series Of Monographs, Vol. 35; John Wiley \& Sons, Inc.: Hoboken, NJ, U.S.A., 1979. doi:10.1002/9780470187333

3. Brown, D. J. Quinoxalines: Supplement II; Chemistry of Heterocyclic Compounds: A Series Of Monographs, Vol. 61; Wiley-Interscience: New York, NY, U.S.A., 2004. doi:10.1002/0471533408

4. Mamedov, V. A. Quinoxalines; Springer International Publishing: Cham, Switzerland, 2016. doi:10.1007/978-3-319-29773-6

5. Li, G.; Wu, Y.; Gao, J.; Wang, C.; Li, J.; Zhang, H.; Zhao, Y.; Zhao, Y.; Zhang, Q. J. Am. Chem. Soc. 2012, 134, 20298-20301. doi:10.1021/ja310131k

6. Gu, P.-Y.; Zhao, Y.; He, J.-H.; Zhang, J.; Wang, C.; Xu, Q.-F.; Lu, J.-M.; Sun, X. W.; Zhang, Q. J. Org. Chem. 2015, 80, 3030-3035. doi:10.1021/j05027707

7. Li, J.; Chen, S.; Wang, Z.; Zhang, Q. Chem. Rec. 2016, 16, 1518-1530. doi:10.1002/tcr.201600015

8. Harley-Mason, J.; Laird, A. H. Tetrahedron 1959, 7, 70-76. doi:10.1016/0040-4020(59)80053-3

9. Yagi, K.; Nagatsu, T.; Nagatsu, I. Nature 1960, 186, 310-311. doi:10.1038/186310a0

10. Asahara, T.; Seno, M.; Teshirogi, T. Bull. Chem. Soc. Jpn. 1971, 44, 1687-1689. doi:10.1246/bcsj.44.1687

11. Armand, J.; Boulares, L.; Bellec, C.; Pinson, J. Can. J. Chem. 1987, 65, 1619-1623. doi:10.1139/v87-271

12. Badger, G. M.; Pettit, R. J. Chem. Soc. 1951, 3211. doi:10.1039/jr9510003211

13. Burrows, A. D. Crystal Engineering Using Multiple Hydrogen Bonds. In Supramolecular Assembly via Hydrogen Bonds I; Mingos, D. M. P., Ed.; Structure and Bonding, Vol. 108; Springer Berlin: Berlin, Germany, 2003; pp 55-96. doi:10.1007/b14137

14. Desiraju, G. R., Ed. Crystal Design: Structure and Function; John Wiley \& Sons: Chichester, United Kingdom, 2003.

15. Gotoh, K.; Asaji, T.; Ishida, H. Acta Crystallogr., Sect. C: Cryst. Struct. Commun. 2007, 63, o17-o20. doi:10.1107/s0108270106049468

16. Czapik, A.; Gdaniec, M. Acta Crystallogr., Sect. C: Cryst. Struct. Commun. 2010, 66, o356-0360. doi:10.1107/s0108270110021736

17. Desiraju, G. R. Angew. Chem., Int. Ed. Engl. 1995, 34, 2311-2327. doi:10.1002/anie.199523111

18. Kobayashi, T.; Kobayashi, S. Eur. J. Org. Chem. 2002, 2066-2073. doi:10.1002/1099-0690(200207)2002:13<2066::aid-ejoc2066>3.0.co;28

19. Chen, M.; Hu, X.; Liu, J.; Li, B.; Leung, N. L. C.; Viglianti, L.; Cheung, T. S.; Sung, H. H. Y.; Kwok, R. T. K.; Williams, I. D.; Qin, A.; Lam, J. W. Y.; Tang, B. Z. Chem. Sci. 2018, 9, 7829-7834. doi:10.1039/c8sc02810a

20. Ono, K.; Okazaki, Y.; Ohkita, M.; Saito, K.; Yamashita, Y. Heterocycles 2004, 63, 2207-2210. doi:10.3987/com-04-10173

21. Easley, W. K.; Bahner, C. T. J. Am. Chem. Soc. 1950, 72, 3803-3805. doi:10.1021/ja01164a509

22. Gaussian 09, Revision A.02; Gaussian Inc.: Wallingford, CT, U.S.A., 2009.

23. Wang, Y.; Wu, J. I.-C.; Li, Q.; von Ragué Schleyer, P. Org. Lett. 2010, 12, 4824-4827. doi:10.1021/ol102012d

24. Etinski, M.; Marian, C. M. Phys. Chem. Chem. Phys. 2017, 19, 13828-13837. doi:10.1039/c7cp02022h

25. Lias, S. G.; Liebman, J. F.; Levin, R. D. J. Phys. Chem. Ref. Data 1984, 13, 695-808. doi:10.1063/1.555719

\section{License and Terms}

This is an Open Access article under the terms of the Creative Commons Attribution License (http://creativecommons.org/licenses/by/4.0). Please note that the reuse, redistribution and reproduction in particular requires that the authors and source are credited.

The license is subject to the Beilstein Journal of Organic Chemistry terms and conditions: (https://www.beilstein-journals.org/bjoc)

The definitive version of this article is the electronic one which can be found at: doi:10.3762/bjoc. 15.203 